\title{
CiDATAnia - Sociedade e Estatística: a construção de um índice regional de preços ao consumidor
}

\section{Chrystian Soares Mendes}

Universidade Federal de Ouro Preto | Brasil

chrystiansm@hotmail.com

\section{Thiago de Sousa Barros}

Universidade Federal de Ouro Preto | Brasil

tsousabarros@gmail.com

\section{Resumo}

Os indicadores nacionais de preços ao consumidor comumente utilizados não contemplam as características de determinados municípios, o que é importante para a compreensão das oscilações de preços regionais e cálculo do custo de vida local. 0 presente artigo retrata o desenvolvimento do projeto de extensão CiDATAnia - Sociedade e Estatística, um programa desenvolvido na Universidade Federal de Ouro Preto (UFOP) que tencionou criar o Índice Geral de Preços ao Consumidor da cidade de Mariana (MG). Os resultados indicam que há discrepâncias entre os resultados das oscilações no índice local e de outros indicadores similares o que enfatiza a importância do projeto para a comunidade marianense.

\section{Palavras-chave}

Inflação; Consumidor; Mariana (MG). 


\section{Introdução}

A inflação, isto é, o aumento generalizado dos níveis de preços, é um dos processos que afetam todas as economias mundiais. 0 Brasil passou por um processo inflacionário que impactou de maneira expressiva a economia do país, principalmente em meados das décadas de 80 e 90 (GIAMBIAGI et al., 2005). Com a criação de uma nova moeda (o Real, a partir de 1994) houve um maior controle inflacionário na economia, acompanhada de políticas monetárias mais rígidas (MODENESI, 2005).

A taxa de juros básica Selic (Sistema Especial de Liquidação e Custódia) é o principal instrumento adotado pelo Banco Central para manter a inflação oficial (CARVALHO et al., 2007; LOPES E ROSSETI, 2005; MODONESI, 2005), sendo medida pelo Índice de Preços ao Consumidor - IPC, que fornece a variação dos preços dos produtos da cesta básica. O IPC é medido por diversas instituições como Fundação Getúlio Vargas (FGV) e Instituto Brasileiro de Geografia e Estatística (IBGE), bem como diversas universidades. Em Minas Gerais, são cerca de seis instituições de ensino superior que fazem sua mensuração, a saber: UFU, UNIMONTES, UFMG, UFV, UFJF e UFLA.

Nesse sentido, tem-se observado a grande relevância que a região de Ouro Preto/Mariana possui na área em que se localiza, uma vez que possui uma crescente atuação de atividades de mineração, o que impacta de maneira expressiva o consumo na região, não tendo na mesma nenhuma instituição que faça a mensuração da cesta de consumo, o que é assaz importante para permitir à sociedade uma medida precisa de itens substituíveis que se tornaram mais caros num mês, bem como outros que se tornaram mais acessíveis. Percebe-se assim, a importância de verificar como se comportam os preços na região, além de corroborar para reforçar o papel preponderante que a Universidade Federal de Ouro Preto possui e contribuir ainda mais para o desenvolvimento econômico e social nas cidades em que se encontra.

Ante tais aspectos, foi proposto a criação de um projeto de extensão para essa finalidade, designado CiDATAnia - Sociedade e Estatística. Em síntese, este projeto propôs a criação do IPCMariana, um índice de preços do consumidor da região, além do desenvolvimento de boletins mensais que informa a sociedade as principais variações de preços ocorridas e indica alternativas de bens substitutos com preços inferiores, contribuindo, portanto, para a comunidade local e alcançando os preceitos fundamentais da atividade extensionista, pois, como ressalta Nogueira (2001, p. 57), a extensão "é um meio pelo qual a Universidade vai cumprir sua função social”. 


\section{Perspectiva histórica da construção de índices de inflação}

O levantamento sistemático de preços possibilita mensurar o poder de compra real de determinada população, durante um período de tempo. Destarte, a sociedade acompanhará as oscilações de preços ocorridas, enquanto a política econômica analisará a situação do efetivo valor da moeda nacional dentro do país, sendo a construção de um índice de preços, portanto, a forma mais fiel de mensurar tal condição (CARVALHO et al, 2007; LOPES E ROSSETI, 2005; COSTA, 1999).

Não obstante, o Banco Central do Brasil - BACEN (2015, p. 2) afirma que "os índices de preços são números que agregam e representam os preços de determinada cesta de produtos. Sua variação mede, portanto, a variação média dos preços dos produtos dessa cesta". Sob esse enfoque, Furtado (2000) relata que a Europa foi precursora na elaboração desse tipo de índice, quando foram percebidas variações nos preços de metais preciosos, produtos estes que entravam em abundância nos países europeus. A posteriori, tais variações também foram observadas em transações de mercadorias, em especial nos anos de guerra.

No Brasil, os levantamentos de preços começaram a ser realizados por volta de 1920 , tomando como base o ano de 1912. Mas somente a partir dos anos 1940 é que foi instituído um conjunto de índices capazes de designar o custo de vida, a fim de atender a legislação do salário mínimo vigente. Assim, esse levantamento permitiu, após alguns ajustes, constituir o Índice Nacional de Preços ao Consumidor (INPC), calculado e divulgado mensalmente pelo Instituto Brasileiro de Geografia e Estatística (IBGE) (FURTADO, 2000).

Segundo Oliveira et al (2010) com a criação do INPC, a Fundação Getúlio Vargas (FGV) passa a contribuir e desempenhar um papel importante na construção de indicadores de preços para a economia brasileira, adotando para isso informações da Pesquisa de Orçamento Familiar (POF) realizada pelo IBGE.

Insta apregoar que com a implementação do Plano Real, em 1994, e principalmente com a adoção do regime de metas de inflação, em 1999 (acompanhando países que já haviam aderido ao sistema como: Nova Zelândia, Canadá, Chile, Reino Unido, Israel, Suécia, entre outros), essa coleta de preços tornou-se relevante para o cenário econômico (BACEN, 2011), uma vez que o controle inflacionário solidificou-se como política monetária essencial sob condução do Banco Central do Brasil (CARVALHO et al, 2007; LOPES e ROSSETI, 2005).

De acordo com Bacen (2015, p. 2) o cálculo de um índice de preço aglutina uma gama de aspectos metodológicos, destacando-se a definição: 
i) do objetivo do índice de preço (por exemplo, o índice pode medir a inflação sofrida pelos empresários do ramo de construção, pelos consumidores em geral, pelos consumidores de baixa renda, etc); ii) da região de coleta, item diretamente ligado ao objetivo do índice (por exemplo, o IPC-Fipe é coletado apenas no município de São Paulo-SP); iii) das fontes e formas de coleta: tipo e tamanho de pontos comerciais, setores pesquisados, forma de entrevista (pessoal ou telefônica), entre outros; iv) da periodicidade da coleta: mensal ou trimestral, por exemplo; v) de quais bens e/ou serviços serão incluídos na cesta a ser pesquisada (por exemplo, o IBGE utiliza a Pesquisa de Orçamentos Familiares (POF) para identificar os bens e serviços mais consumidos por cada faixa de renda, e assim constrói as cestas que compõem o IPCA, o IPCA-15 e o INPC); vi) da metodologia do cálculo, que definirá como combinar em única medida estatística a variação do preço do conjunto de bens e dos serviços pesquisados (duas metodologias comuns são a de Laspeyres e a de Paasche).

Dadas essas distinções e diversidades, vários índices foram construídos no Brasil ao longo do Século 20 por instituições diversas - tais como: o Instituto Brasileiro de Geografia e Estatística (IBGE), o Instituto Brasileiro de Economia da Fundação Getúlio Vargas (FGV) e a Fundação Instituto de Pesquisas Econômicas (Fipe) - e com finalidades díspares - como, por exemplo, os seguintes índices: IPC (Índice de Preços ao Consumidor), IPCA (Índice Nacional de Preços ao Consumidor Amplo), o INPC (Índice Nacional de Preços ao Consumidor), o IPA (Índice de Preços ao Produtor Amplo), o INCC (Índice Nacional de Custo da Construção), o IGP-M (Índice Geral de Preços - Mercado), e IGP-DI ((Índice Geral de Preços - Disponibilidade Interna).

Desse modo, sendo a inflação, isto é, o aumento generalizado dos níveis de preços, um dos processos que afetam todas as economias mundiais, os indicadores de inflação passaram a desempenhar papel preponderante para avaliação da estabilidade econômica do país (MANKIW, 2015; DORNBUSCH et al, 2013; FROYEN, 2013; e MISHKIN, 1998). Contudo, tais indicadores não inferem de forma específica as particularidades de cada município. Sendo assim, índices regionais têm sido cada vez mais presentes nos dias de hoje, com o intuito de contornar e mensurar de forma mais precisa as especificidades locais (OLIVEIRA et al, 2010).

Por isso, em face da evidência latente de que a abrangência geográfica desses índices limita-se a algumas regiões metropolitanas do país e, por conseguinte, alguns indicadores nacionais podem não acompanhar a realidade regional de determinados locais no que tange a variação de preços, procurou-se, por meio do Programa de Extensão CiDATAnia - Sociedade \& Estatística, realizado pelo Departamento de Ciências Econômicas e Gerenciais da Universidade Federal de Ouro Preto, construir o Índice de Preços ao Consumidor da cidade de Mariana em Minas Gerais, visando captar as oscilações de preços ocorridas no município e seus reflexos, um projeto capaz de contribuir para a comunidade com dados que incentivem o consumo consciente e facilitem o planejamento financeiro familiar.

Pesquisas similares já foram conduzidas em outros municípios do Estado, principalmente aqueles que possuem universidades locais, casos de Belo Horizonte, Viçosa, 
Governador Valadares, Juiz de Fora, Uberlândia, Lavras, entre outros. Aproveitando esses dados, o projeto CiDATAnia realiza comparações dos resultados obtidos na pesquisa com os índices de preços ao consumidor dessas outras regiões e do índice nacional, e enfatiza as principais discrepâncias ocorridas nos diversos itens que compõem as cestas de compras dessas localidades.

\section{O Projeto de Extensão CiDATAnia - Sociedade \& Estatística}

A cidade de Mariana, considerada a primeira capital mineira do Estado de Minas Gerais, é uma das regiões de maior extração mineral do país. Localizada a 12 quilômetros da cidade de Ouro Preto e cerca de 122 quilômetros da capital Belo Horizonte, abrange cerca de 12 distritos, os quais desenvolvem atividades de mineração e artesanato, com a produção de peças em pedra sabão. Apesar de possuir uma população de aproximadamente 58 mil habitantes, a cidade é a décima na participação do Produto Interno Bruto (PIB) do Estado e a $112^{\circ}$ no ranking nacional de 2014 (IBGE, 2013).

Observado a grande relevância socioeconômica que a região de Mariana possui em Minas Gerais e para os distritos e cidades adjacentes, percebe-se a importância da criação de mecanismos que possibilitem e facilitem uma melhor análise do perfil econômico regional. É nesse cenário que o projeto CiDATAnia - Sociedade \& Estatística surgiu para implementar o índice de preços ao consumidor local, uma iniciativa dos professores de Economia e Estatística da UFOP.

Como bem apregoa Jezine (2001, p. 130-131):

A Extensão Universitária surge como instrumento a ser utilizado pela Universidade para a efetivação do seu compromisso social e também como articuladora das suas relações. Ela vai receber, desde o seu início, a responsabilidade de efetivar este compromisso com as comunidades. Esse papel articulador não deve, necessariamente, ser visto como a substituição para falhas no Ensino e na Pesquisa. Trata-se de um momento de construção em que Extensão Universitária é uma ferramenta necessária e útil para tornar os produtos da Universidade mais próximos da sociedade.

Não obstante, o projeto em voga objetivou aproximar conceitos econômicos da comunidade marianense, o que sublinha a importância do mesmo para a sociedade local, uma vez que os consumidores da região, por meio dos índices gerados nesta pesquisa, poderão melhorar as decisões de consumo e conhecer como as variações ocorridas nos itens avaliados pela pesquisa afetam o orçamento doméstico, o que está em plena consonância com os argumentos erigidos por Batomé (2001, p. 167) de que "a extensão universitária deverá sempre 
ser um tipo de atividade que potencializa as possibilidades de acesso ao conhecimento que o ensino regular e a pesquisa ainda não realizam".

Nesse mesmo diapasão, é pertinente citar o célebre educador Paulo Freire, que dispunha sobre a importância da extensão universitária alegando que "o conhecimento não se estende do que se julga sabedor até aqueles que se julga não saberem" (...) uma vez que se "constitui nas relações homem-mundo, relações de transformação, e se aperfeiçoa na problematização crítica destas relações" (FREIRE, 2006, p. 36).

Por isso, além do envolvimento da comunidade de Mariana, o projeto de extensão ora em apreço foi fundamental para que os bolsistas colocassem em prática os conhecimentos adquiridos ao longo da graduação em ciências econômicas - tendo em vista que eles carecem de atividades práticas ao longo do curso -, visualizassem a realidade da economia do município e enriquecessem suas respectivas formações através das relações diretas com a sociedade na qual a universidade encontra-se inserida, expandindo o espaço de aprendizagem para além dos muros do Instituto de Ciências Sociais Aplicadas da UFOP.

Ademais, o Índice de Preços ao Consumidor de Mariana (IPC-MARIANA) é um indicador do custo de vida no município. 0 termo "custo de vida" se refere à relação existente entre a quantidade de bens e serviços que um consumidor pode adquirir em dado período de tempo, isto é, mede o quanto um indivíduo dispõe de sua renda para manter a mesma satisfação nesse período. Assim, o IPC- MARIANA tem a finalidade de medir a dinâmica de preços de um conjunto preestabelecido de bens e serviços consumidos pela população de Mariana. A seguir serão demonstrados os bens e serviços que serão parte do índice, bem como a importância relativa de cada item (Figura 1).

Transcendendo tais questões, sabe-se que o IPC-MARIANA é, portanto, um númeroíndice que mede a variação dos preços de bens e serviços consumidos pela população marianense, em uma escala temporal. A fórmula para se calcular é feita utilizando-se como base o índice de Laspeyres, adotado também pelo Instituto Brasileiro de Geografia e Estatística, IBGE, o qual pressupõe uma estrutura de pesos constante no tempo, tendo como base o período inicial da amostra. A expressão (1) apresenta sua formatação:

$$
L_{o, t}=\frac{\sum_{i=1}^{n}\left(p_{t}^{i}\right) \times\left(q_{0}^{i}\right)}{\sum_{i=1}^{n}\left(p_{0}^{i}\right) \times\left(q_{0}^{i}\right)}
$$

O índice de Laspeyres mede a variação do nível de preços, considerando a mesma cesta de consumo, do período 0 (período-base) ao $\mathrm{t}$ (período correte). A variável $\mathrm{p}_{\mathrm{t}}^{\mathrm{i}}$ representa o 
preço do subitem "i" no tempo " $\mathrm{t}$ "; $\mathrm{p}_{0}^{\mathrm{i}}$, o preço do mesmo item no período base; e $\mathrm{q}_{0}^{\mathrm{i}}$ a quantidade consumida do bem no período base.

Nesse sentido, o IPC-MARIANA, bem como os demais índices de preços a nível nacional, mede a inflação na perspectiva do consumidor típico. Exclui-se, assim, os perfis de consumo extremos, como famílias com rendimento abaixo de 1 salário mínimo e acima de 40, em razão da heterogeneidade apresentada em suas cestas de consumo em relação à média. Segundo o IBGE (2013), isso indica a exclusão de cerca de 8,5\% das famílias analisadas. Portanto, o IPCMARIANA contempla famílias que residem em área urbana, com rendimentos entre 1 e 40 salários mínimos.

Ademais, o IPC-MARIANA está subdividido em sete itens, a saber: alimentação e bebidas, vestuário, habitação, artigos de residência, transporte e comunicação, saúde e cuidados pessoais, educação e despesas pessoais. A estrutura dos pesos é apresentada por meio da Figura 1, em que a soma de todos os pesos é igual à unidade (01).
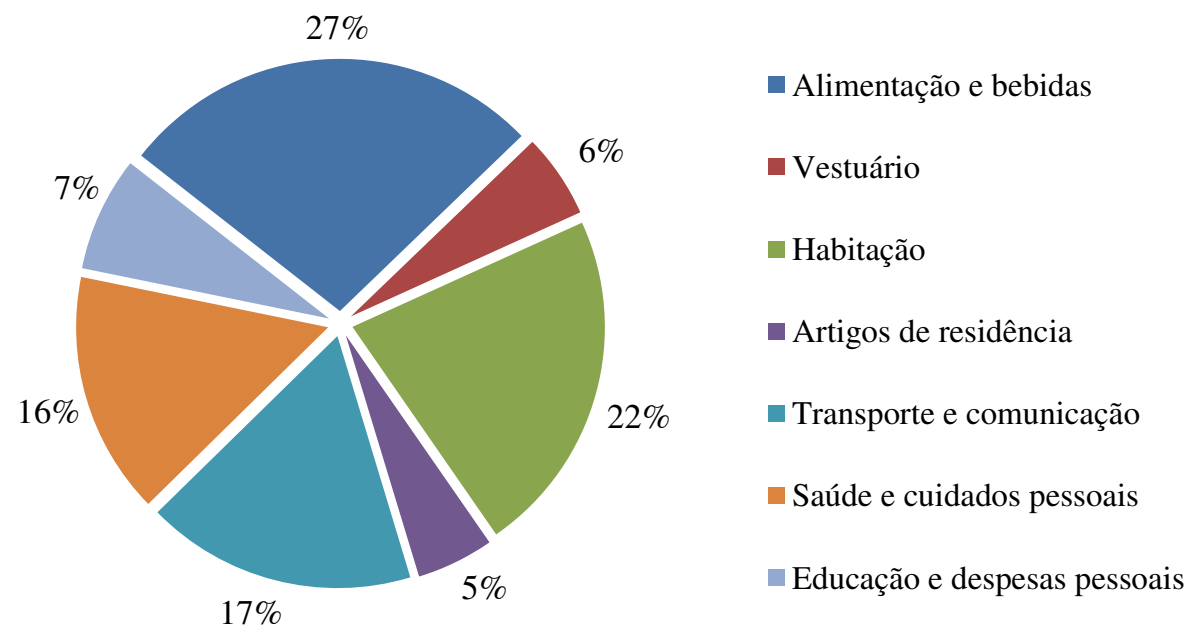

Figura 1: Distribuição percentual dos pesos por grupo.

Fonte: Elaboração própria

Os pesos adotados nos grupos foram feitos utilizando como base os índices da Universidade Federal de Juiz de Fora/Campus Governador Valadares e da Universidade Federal de Viçosa/DEE, isto é, parte-se do pressuposto que o perfil de consumo da cidade de Mariana Minas Gerais é semelhante ao dos municípios de Viçosa e Governador Valadares.

Dessa feita, o IPC-MARIANA pesquisa os preços de 424 produtos e serviços, entre os dias 10 e 20 de cada mês, em cerca de 60 estabelecimentos, em que conta com a participação de sete bolsistas sendo cinco deles voluntários. Ao final de cada período, o Departamento de Ciências 
Econômicas e Gerencias - DECEG/UFOP, por meio do projeto de extensão CiDATAnia - Sociedade e Estatística, disponibiliza o relatório da variação dos preços à comunidade em geral.

Mensalmente são divulgados relatórios mensais sobre a variação dos preços da cesta básica, estruturada a partir da cesta básica oficial do DIEESE - Departamento Intersindical de Estatística e Estudos Socioeconômicos, em consonância com o Decreto Lei no399 de 30 de abril de 1938, o qual estipula os produtos e quantidades necessárias para um indivíduo adulto que recebe um salário mínimo. Por meio desse cálculo é possível estimar as horas de trabalho necessárias para adquirir a cesta padrão, o que permite disponibilizar para a população marianense mais um indicador do custo de vida da cidade.

Conforme o Decreto Lei no 399/1938 retromencionado, a cesta básica padrão, também conhecida como ração essencial mínima, é constituída por 13 produtos alimentícios. Além disso, o Decreto estabelece que "o salário mínimo é a remuneração devida do trabalhador adulto, sem distinção de sexo, por dia normal de serviço, capaz de satisfazer em determinada época e região do país suas necessidades normais de alimentação, habitação, vestuário, higiene e transporte" (BRASIL, 1938).

Neste sentido, o projeto de extensão ora em apreço, ao acompanhar mensalmente as variações nesses produtos (por meio da criação do Índice de Preços de Mariana), fornecerá uma estimativa do gasto mensal que o trabalhador terá de realizar para comprá-los e da importância relativa da cesta básica em termos do salário mínimo vigente.

Após uma pesquisa realizada em âmbito nacional, as Comissões do Salário Mínimo definiram as cestas básicas suficientes para suprir as quantidades balanceadas de proteínas, calorias, ferro e fósforo em cada região brasileira. Conhecido o preço médio de cada item da ração mínima, levantado pelo IPC-MARIANA, pode-se obter o gasto total com a cesta básica pela simples multiplicação dos preços e quantidades de alimentos, definidas pelo Decreto Lei $\mathrm{n}^{\circ} 399$. Por fim, o cálculo das horas que o trabalhador remunerado pelo salário mínimo precisa trabalhar para comprar a cesta básica é feito pela seguinte fórmula:

$$
\text { horas }=\frac{\text { custo da cesta }}{\text { salário mínimo }} \times 220 \text {. }
$$

Na fórmula (2) o número 220 representa as horas totais de trabalho em um mês, conforme regulamentado pela legislação brasileira. O valor vigente do salário mínimo corresponde a $\mathrm{R} \$ 788,00$, desse modo, basta dividir o custo da cesta básica por esse valor e multiplicar por 220 para que assim se obtenha a quantidade de horas necessárias para aquisição da cesta básica padrão. 
CiDATAnia - Sociedade e Estatística: a construção de um índice regional de preços ao consumidor

Em suma, espera-se que tal iniciativa contribua de maneira expressiva para as políticas públicas da região, bem como permita aos cidadãos de Mariana uma visão mais apurada da realidade socioeconômica e das variações dos preços dos produtos e serviços fornecidos no município, possibilitando a eles realizarem substituições nas compras desses bens.

\section{Resultados alcançados}

Após a divulgação dos primeiros boletins, o projeto de extensão CiDATAnia - Sociedade e Estatística ganhou espaço na imprensa local de Mariana e Ouro Preto, recebendo matérias especializadas nos jornais $O$ Liberal e Ponto Final. Ademais, foram realizadas entrevistas para divulgar o projeto na TV UFOP, levando à comunidade local informações relevantes acerca do custo de vida no município e dando publicidade aos resultados atingidos.

Transcendendo tais questões, que são de grande relevo para a atividade extensionista na árdua tarefa de aproximar Universidade e Sociedade, o projeto contou também com vasto apoio dos discentes, bem como da população marianense, que passou a utilizar o índice como um importante indicador da economia regional e pôde extrair, dos relatórios gerados, explicações acerca das oscilações de preços de uma gama de produtos, melhorando, destarte, o ato de consumo.

Por este vértice de análise, insta aduzir que o projeto busca também atacar este ponto central: fazer com que os indivíduos da sociedade de Mariana possam, por meio da formação e dos índices criados, conscientizar-se da possibilidade de adquirir substitutos no momento de compra e melhorar a saúde financeira do orçamento familiar por meio de um consumo racionalizado e eficiente. Por isso, ao observar a positiva recepção inicial da população com o projeto e a alegação por parte de seus integrantes da utilidade prática dos indicadores gerados, o CiDATAnia - Sociedade e Estatística atinge um de seus principais objetivos.

Os resultados da pesquisa também indicam que o IPC-MARIANA, até o período de setembro de 2015, realizou cinco Boletins Informativos, os quais apresentaram informações sobre os principais produtos que sofreram elevação e queda de preços de um mês para outro, além de exibir os custos para aquisição da cesta básica padrão e a quantidade de horas para sua aquisição. Os Boletins foram divulgados mensalmente à comunidade marianense por meio digital e impresso.

Ao longo desse período (maio a setembro/2015), a inflação de Mariana registrou um acumulo de 3,75\%, com destaque para os itens Alimentação (1,01\%), Habitação $(0,82 \%)$, Saúde $(0,58 \%)$ e Transporte e Comunicação (0,58\%), como mostra a Tabela 1, a seguir. 
CiDATAnia - Sociedade e Estatística: a construção de um índice regional de preços ao consumidor

Tabela 1 - IPC -Mariana por grupos de despesas, de maio a julho, e acumulado

\begin{tabular}{l|c|c|c|c|c|c}
\hline GRUPO & MAI & JUN & JUL & AGO & SET & ACUMULADO \\
\hline Alimentação & 0,16 & 0,18 & 0,16 & 0,03 & 0,48 & 1,01 \\
\hline Habitação & 0,13 & 0,15 & 0,13 & 0,02 & 0,39 & 0,82 \\
\hline $\begin{array}{l}\text { Transporte e } \\
\text { comunicação }\end{array}$ & 0,04 & 0,12 & 0,10 & 0,02 & 0,30 & 0,58 \\
\hline Saúde & 0,10 & 0,10 & 0,09 & 0,02 & 0,27 & 0,58 \\
\hline Educação & 0,09 & 0,05 & 0,04 & 0,01 & 0,13 & 0,32 \\
\hline Vestuário & 0,03 & 0,04 & 0,07 & 0,01 & 0,09 & 0,24 \\
\hline Artigos de residência & 0,03 & 0,03 & 0,03 & 0,01 & 0,09 & 0,19 \\
\hline IPC-MARIANA & $\mathbf{0 , 5 8}$ & $\mathbf{0 , 6 7}$ & $\mathbf{0 , 6 2}$ & $\mathbf{0 , 1 1}$ & $\mathbf{1 , 7 5}$ & $\mathbf{3 , 7 5}$ \\
\hline
\end{tabular}

Fonte: IPC-MARIANA/DECEG/UFOP.

Observa-se que a inflação acumulada de Maio a Setembro em Mariana (3,75\%) foi superior que a inflação estimada pelo Índice de Preços ao Consumidor Amplo (IPC-A), calculado pelo IBGE, que registrou expansão de 2,91\% no mesmo período.

Pode-se destacar ainda que o IPC-MARIANA apresentou comportamento similar aos índices nacionais no que tange a elevação e redução. Contudo, apesar da semelhança, os valores obtidos pelo índice local ficaram em sua maior parte, abaixo do Índice Nacional de Preço ao Consumidor-INPC e do Índice de Preço ao Consumidor Amplo-IPCA, calculados pelo IBGE, como observado pela Figura 2, a seguir.

Vale salientar que no mês de setembro/2015 o valor registrado pelo IPC-Mariana foi superior aos índices destacados, o que demonstra que a realidade local na maioria das vezes não reflete os impactos em níveis nacionais que em muitos casos podem ser maiores ou menores para dada região do país, como foi no município de Mariana-MG.

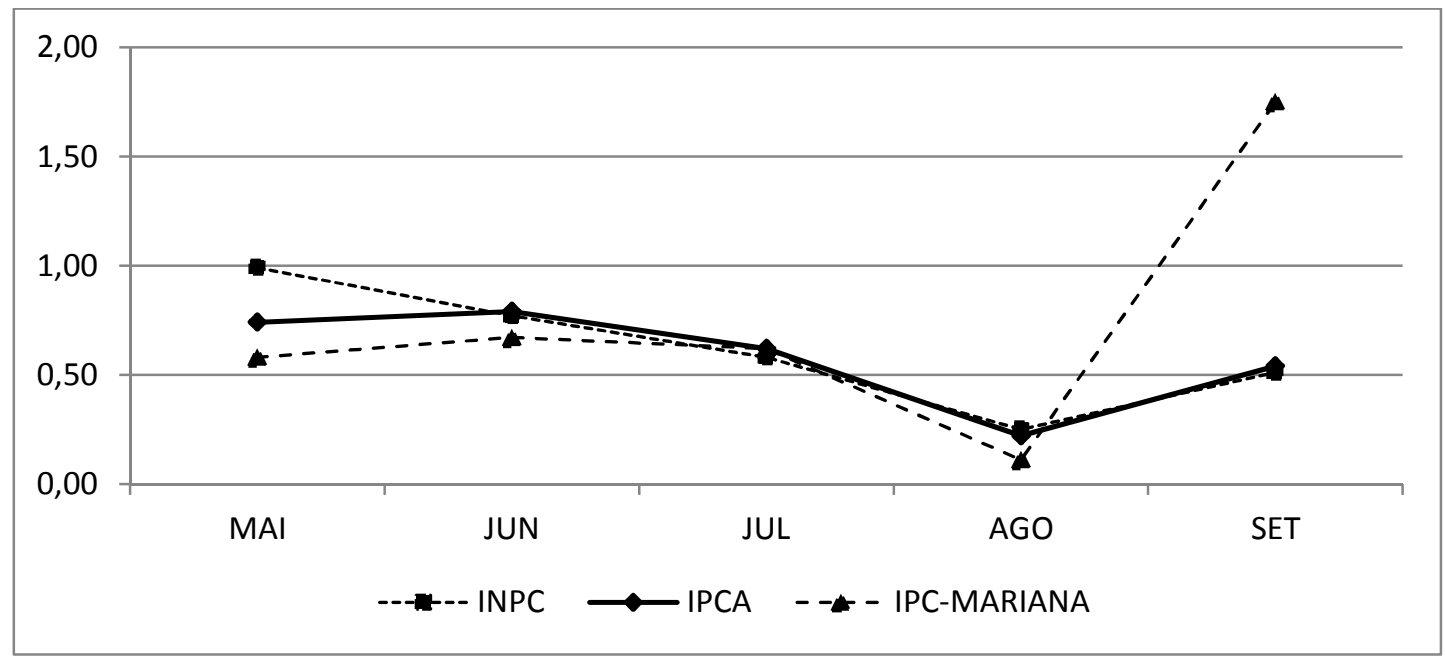

Figura 2: Evolução dos índices INPC, IPCA e IPC-MARIANA, no período de maio a setembro de 2015 no Brasil e em Mariana (MG).

Fonte: IBGE/FGV/DIEESE. 
CiDATAnia - Sociedade e Estatística: a construção de um índice regional de preços ao consumidor

Um dos fatores que pode ter contribuído foi o alto custo de produtos que compõem a cesta básica e que tiveram aumento no mês de setembro. Produtos como carne, arroz, verduras e legumes, além dos combustíveis que sofreram grande elevação, e do gás de cozinha que tem importante participação na cesta de consumo do trabalhador, variou cerca de 12,5\% em relação ao mês de agosto. A alta do dólar e também dos preços administrados (como combustíveis, energia etc.) tem pressionado os preços em 2015.

Em relação à cesta básica, ao longo dos cinco meses de realização do projeto de extensão, observou-se que o custo para sua aquisição foi em média de $\mathrm{R} \$ 349,32$, o que corresponde a $44,32 \%$ de um salário mínimo de $\mathrm{R} \$ 788,00$ de um trabalhador, tendo este que utilizar os outros $55,68 \%$ do salário para itens como saúde, transporte, educação, lazer etc. É notória a dificuldade de uma família de quatro membros para se manter de forma satisfatória com apenas uma salário mínimo, e atender todas as suas necessidades básicas, sendo preciso trabalhar cerca de 97,52 horas por mês somente para adquirir uma cesta básica nos moldes da estrutura do DIEESE, como pode ser verificado pela Tabela 2 .

Tabela 2 - Custo da cesta básica em Mariana/MG, Agosto/Setembro, 2015.

\begin{tabular}{l|c|c|c|c|c|c|c|c}
\hline \hline Produtos & Medida & Qtde & $\begin{array}{c}\text { Proporção } \\
\text { da Qtde }\end{array}$ & $\begin{array}{c}\text { Preço } \\
\text { Ago. 2015 }\end{array}$ & QtxP & $\begin{array}{c}\text { Preço } \\
\text { Set. 2015 }\end{array}$ & $\begin{array}{c}\text { Qtx P } \\
\text { Variação } \\
\text { (\%) }\end{array}$ \\
\hline \hline Carne & $\mathrm{Kg}$ & 6 & 6 & 17,2 & 103,3 & 20,8 & 125,0 & 21.1 \\
Leite & $\mathrm{L}$ & 7,5 & 7,5 & 2,6 & 19,4 & 2,4 & 17,9 & -7.4 \\
Feijão & $\mathrm{Kg}$ & 4,5 & 4,5 & 3,6 & 16,1 & 3,6 & 16,2 & 1.1 \\
Arroz & $\mathrm{Kg}$ & 3 & 3 & 12,6 & 7,6 & 13,2 & 7,9 & 4.9 \\
Farinha de trigo & $\mathrm{Kg}$ & 1,5 & 1,5 & 2,6 & 3,9 & 2,6 & 3,9 & 2.0 \\
Batata & $\mathrm{Kg}$ & 6 & 6 & 2,5 & 14,9 & 2,4 & 14,4 & -3.0 \\
Tomate & $\mathrm{Kg}$ & 9 & 9 & 3,3 & 29,8 & 3,5 & 31,5 & 5.9 \\
Pão Francês & $\mathrm{Kg}$ & 6 & 6 & 10,1 & 60,8 & 11,0 & 65,9 & 8.5 \\
Café em pó & $\mathrm{Kg}$ & 0,6 & 1,2 & 4,8 & 5,8 & 4,8 & 5,7 & -0.5 \\
Banana & $\mathrm{Kg}$ & 90 & 9 & 2,4 & 21,9 & 3,4 & 30,3 & 38.4 \\
Açúcar & $\mathrm{Kg}$ & 3 & 3 & 6,6 & 3,9 & 6,7 & 4,0 & 2.6 \\
Óleo & $\mathrm{Ml}$ & 750 & 0,79 & 2,8 & 2,2 & 3,4 & 2,7 & 19.0 \\
Manteiga & $\mathrm{Kg}$ & 0,75 & 3 & 4,1 & 12,4 & 6,1 & 18,3 & 48.2 \\
\hline Gasto total
\end{tabular}

Fonte: Elaborado pelos autores.

(*) NOTA: A coluna Qt x P pode ser obtida padronizando o preço do produto no mês de análise pelas quantidades existentes na cesta básica, diferentes das unidades dos pacotes encontrados no comércio.

Para fins de simplificação, a Tabela 2 apresenta a variação da cesta básica do mês de Agosto para Setembro de 2015. Com base nos dados apresentados, percebe-se que os preços da cesta de consumo se elevaram cerca de 14\% em Setembro. Os custos totais para se obter a cesta 
básica no município foram de $\mathrm{R} \$ 344,08$, sendo preciso trabalhar agora cerca de 96,06 horas, em relação ao salário mínimo, estabelecido em $\mathrm{R} \$ 788,00$. 0 aumento da cesta em relação à Agosto foi de aproximadamente $\mathrm{R} \$ 42,29$, ou seja, ficaram mais caros os produtos da cesta, como bem representou a Tabela 2 .

Praticamente todos os itens da cesta básica sofreram aumento, com exceção do Leite ($7,4 \%)$, Batata $(-3,0 \%)$ e do Café em pó $(0,5 \%)$. Dos demais itens da cesta que tiveram aumento o destaque ficou por conta da Manteiga (48,2\%), da Banana (38,4\%), do Arroz (21,1\%) e do Óleo (19\%). Percebe-se, assim, que a cesta básica representou uma parcela maior da renda do trabalhador, cerca de $43,37 \%$. 0 trabalhador terá que despender mais horas trabalhadas para adquirir a cesta de consumo, devido à elevação que sofreram os diversos produtos já mencionados, como o Arroz e Óleo.

Esse aumento na cesta básica pode ser percebido ao se comparar com o preço da cesta de outras regiões, como é o caso da cidade de Viçosa, em que a cesta ficou em torno de $\mathrm{R} \$$ 262,10 , sendo que a de Mariana foi de $R \$ 344,08$, uma diferença de $R \$ 81,98$, um valor substancial, dado que no mês de Setembro a cesta básica correspondeu a $43 \%$ da renda total do trabalhador.

Em síntese, tais valores evidenciam a relevância do índice do IPC-MARIANA, pois possibilita aos consumidores observarem as principais mudanças nos preços dos produtos e assim realizarem substituições, além de reforçar a importância de se fazer pesquisas de preços nos estabelecimentos comerciais antes de concluir a compra do mês.

\section{Considerações finais}

Considerando o atual cenário inflacionário do Brasil e a crescente utilização de índices regionais, o projeto de extensão CiDATAnia - Sociedade e Estatística buscou identificar as variações nos preços dos produtos e serviços no município de Mariana (MG). Nesse sentido, os principais resultados observados ao longo do período de realização da pesquisa indicam que a inflação acumulada do município marianense foi superior à média nacional, isto é, $3.75 \%$ e $2.94 \%$, respectivamente.

Sob esse enfoque, convém assinalar que desses 3.75\% de acúmulo inflacionário, durante os meses de maio a setembro de 2015, os produtos ligados à Alimentação (1,01\%), Habitação $(0,82 \%)$, Saúde $(0,58 \%)$ e Transporte e Comunicação $(0,58 \%)$ foram aqueles que mais contribuíram para esse valor.

As informações geradas no bojo deste projeto contribuíram para um melhor entendimento da comunidade local acerca das oscilações de preços ocorridas na região e 
contaram com ampla aceitação social, levando a própria imprensa de Mariana a aderir e divulgar o índice construído como importante informação econômica do município. Ademais, diversos moradores da cidade ressaltaram a utilidade do indicador para as decisões de consumo, dado que puderam realizar substituições nos processos de compra, trazendo maior eficiência ao orçamento doméstico.

Vale asseverar que ao longo do desenvolvimento da etapa de coleta de preços vários entraves foram notados, a saber: a aceitação do comércio local na cessão de dados relacionados aos preços dos produtos; dificuldades para encontrar o proprietário do estabelecimento; e o número limitado de bolsistas para a realização das atividades de extensão, apesar do envolvimento de alunos voluntários, o que fez superar tal restrição.

Levando em consideração que o projeto de extensão é de natureza contínua, deve-se enfatizar também a necessidade de manter tal iniciativa ao longo do tempo e ampliar o número de índices gerados a fim de abarcar realidades setoriais (como, por exemplo, a criação de um índice para a construção civil, importante segmento da economia local).

Como agenda de pesquisas futuras é assaz relevante destacar que o projeto caminha para sua segunda etapa, na qual cursos de formação relacionados à educação financeira e ao orçamento e planejamento financeiro familiar serão ofertados em escolas públicas (ensino fundamental e médio) e associações de bairros (em especial aquelas localizadas em regiões mais vulneráveis), visando aproximar a universidade da comunidade em seu entorno, elevando o grau de conhecimento das pessoas sobre a necessidade de praticar um consumo consciente e preservar uma situação financeira equilibrada.

\section{Referências}

BACEN - Banco Central do Brasil. Índices de preços no Brasil: com informações até março de 2015. Brasília: BCB, 2015.

BACEN - Banco Central do Brasil. Dez anos de metas para a inflação - 1999-2009. Brasília: Banco Central do Brasil, 2011.

BATOMÉ, S. P. Extensão Universitária: Equívocos, Exigências, Prioridades e Perspectivas para a Universidade. In. FARIA Dóris Santos de. (org.). Construção Conceitual da Extensão Universitária na América Latina. Brasília. UnB, 2001. p. 159 - 175.

BRASIL. Decreto-lei n. 399, 30 de abril de 1938 . Disponível em: $<$ http://legis.senado.gov.br/legislacao/ListaPublicacoes.action?id=12746> Acesso em: 19 fev. 2015.

CARVALHO, F.J.C.; SOUZA, F.P.; SICSU, J. Economia monetária e financeira. Teoria e prática. Campus, 2007. 
COSTA, F. N. Economia monetária e financeira - uma abordagem pluralista. São Paulo: Makron, 1999.

DORNBUSCH, R.; FISCHER, S. e STARTZ, R. Macroeconomia. 11 ed. Porto Alegre: Mc Graw Hill, 2013.

FROYEN, R. T. Macroeconomia: Teorias e aplicações. 2 ed. São Paulo: Editora Saraiva, 2013.

FREIRE, P. Extensão ou comunicação. 13 ed. São Paulo: Paz e Terra. 2006.

FURTADO, M. B. Síntese da economia brasileira. 7 ed. Rio de Janeiro: Livros Técnicos e Científicos, 2000.

GIAMBIAGI, F. et al. Economia brasileira contemporânea. RJ: Elsevier, 2005.

IBGE - Instituto Brasileiro de Geografia e Estatística. Atlas do censo demográfico 2010. Rio de Janeiro:IBGE, 2013.

JEZINE, E. M. Mutiversidade e Extensão Universitária. In: FARIA, Dóris Santos de. (org.). Construção Conceitual da Extensão Universitária na América Latina. Brasília. UnB, 2001. p. 127140.

MANKIW, N. G. Macroeconomia. 8 ed. Rio de Janeiro: LTC (Saraiva), 2015.

MISHKIN, F. S. Moedas, bancos e mercados financeiros. 5 ed. Rio de Janeiro: LTC, 1998.

MODENESI, A. M. Regimes monetários: teorias e a experiência do real. 1 ed. São Paulo: Manole, 2005.

NOGUEIRA, M. D. P. Extensão Universitária no Brasil: uma revisão conceitual. In: FARIA, Dóris Santos de (org.). Construção conceitual da extensão universitária na América Latina. Brasília: Universidade de Brasília, 2001, p. 91-105.

OLIVEIRA, G. S.; ZILLI, J. B.; PEREIRA, A.S. 0 índice de preços de Passo Fundo (RS): análise e relevância. Perspectiva Econômica, v. 6, n. 2, p. 59-79, jul./dez, 2010. 
CiDATAnia - Sociedade e Estatística: a construção de um índice regional de preços ao consumidor

CiDATAnia - Society and Statistics: the construction of a regional consumer prices index

\section{ABSTRACT}

The national consumer price indicators commonly used does not include the features of certain municipalities, which is important for understanding the regional price fluctuations and calculating the cost of local life. This article portrays the development of the project CiDATAnia - Society and Statistics, a program developed at the Federal University of Ouro Preto (UFOP) that tensed to create the General Consumer Price Index for the Mariana City (Minas Gerais, Brazil). The results indicate that there are discrepancies between the results of fluctuations in the local index and other similar indicators which emphasizes the importance of the project for the local (Mariana City) community.

\section{Keywords}

Inflation; Consumer; Mariana (MG).

Original submetido em: 5 out. 2015

Aceito para publicação em: 8 dez. 2015

\section{CiDATAnia - Sociedad y Estadísticas: construcción de un índice regional de precios al consumidor}

\section{RESUMEN}

Los indicadores nacionales de precios al consumidor de uso común no incluyen las características de ciertos municipios, lo que es importante para la comprensión de las fluctuaciones regionales de precios y para calcular el costo de la vida local. En este artículo se describe la evolución del proyecto de extensión CiDATAnia - Sociedad y Estadística, un programa desarrollado en la Universidad Federal de Ouro Preto (UFOP) que tenía el objetivo de crear un Índice General de Precios al Consumidor en la ciudad de Mariana. Los resultados indican que hay discrepancias entre los resultados de las fluctuaciones en el índice local y otros indicadores similares que subraya la importancia del proyecto para la comunidad marianense.

Palabras clave

Inflación; Consumidor; Mariana (MG).

Sobre os autores:

\section{Chrystian Soares Mendes}

Doutor em Economia Aplicada pela Universidade Federal de Viçosa, Professor do Departamento de Ciênias Econômias e Gerencias da Universidade Federal de Ouro Preto, atualmente na área de Macroeconomia e Métodos Quantitativos.

\section{Thiago de Sousa Barros}

Doutorando em Administração pela Fundação Getúlio Vargas, Mestre especialista em Contabilidade e Finanças pela Faculty of Economics of the University of Coimbra. Professor do Departamento de Ciências Econômicas e Gerências da Universidade Federal de Ouro Preto, atualmente na área de Finanças, Administração e Contabilidade Financeira e Mercados de Capitais. 